\title{
Case report. Zeldzame cutane metastasering van urotheelcelcarcinoom twee jaar na cystectomie
}

\author{
Isabel B. de Angst · Joost A. P. Leijte · Olaf J. L. Loosveld · Hans M Westgeest · Ilze E. W. van Onna
}

Published online: 8 January 2020

(c) The Author(s) 2019

\begin{abstract}
Samenvatting Een 77-jarige vrouw presenteerde zich op de polikliniek Dermatologie met een huidafwijking in de linkerlies. In 2016 onderging zij een robotgeassisteerde cystectomie met lymfeklierdissectie en werd een Brickerse deviatie aangelegd vanwege een pT3N1M0G3-urotheelcelcarcinoom (UCC). Postoperatief werd zij aanvullend bestraald, omdat er sprake was van een positief snijvlak. Na twee jaar followup presenteerde patiënte zich met lymfoedeem in haar linkerbeen en een huidafwijking in de linkerlies. Differentiaaldiagnostisch werd gedacht aan eczeem, herpes zoster of metastasen van het eerdere UCC. Een huidbiopt bevestigde de diagnose cutane metastasen van UCC. Cutane metastasen van urogenitale tumoren komen zelden voor en hebben een slechte prognose. Bij een patiënt met een bekend UCC en nieuw ontstane huidafwijkingen dient een cutane metastase daarom in de differentiaaldiagnose te worden meegenomen. Als behandeling kan palliatieve therapie overwogen worden. In deze casus kreeg patiënte chemotherapie.
\end{abstract}

Trefwoorden urotheelcelcarcinoom - cutane metastasen - oncologie

Case report. Rare cutaneous metastases of urothelial cell carcinoma of the bladder two years after cystectomy

Abstract A 77-year-old patient visited the outpatient Dermatology clinic with a skin lesion in her left groin.

drs. I. B. de Angst $(\bowtie) \cdot$ dr. J. A. P. Leijte · drs. I. E. W. van Onna afdeling Urologie, Amphia ziekenhuis, Breda, Nederland ideangst@amphia.nl

dr. O. J. L. Loosveld · drs. H. M. Westgeest afdeling Interne geneeskunde/Oncologie, Amphia ziekenhuis, Breda, Nederland
The patient had a medical history of robot-assisted cystectomy with lymph node dissection and ileal conduit urinary diversion in 2016 because of pT3N1M0G3 urothelial carcinoma (UCC) of the bladder. Due to positive resection margin, she received radiotherapy. After 2 years of follow-up, she developed lymphedema in her left leg and the skin lesion, which was suspect for eczema, herpes zoster or metastases of UCC. Skin biopsy confirmed the diagnosis of cutaneous metastases of UCC. Cutaneous metastases are uncommon for urologic tumors and are associated with poor prognosis. For a patient with known UCC and newly developed skin lesions, it should therefore be included in the differential diagnosis. Palliative therapy can be considered as treatment. In this case, the patient received chemotherapy.

Keywords urothelial carcinoma c cutaneous metastases · oncology

\section{Introductie}

Jaarlijks worden in Nederland circa 6.700 mensen met blaaskanker gediagnosticeerd. In ongeveer $30 \%$ van de gevallen betreft het ten tijde van de diagnose een spierinvasief blaascarcinoom [1]. Indien bij disseminatieonderzoek geen afstandsmetastasen worden aangetoond, is een radicale cystectomie, al dan niet voorafgegaan door neoadjuvante chemotherapie, de behandeling van eerste keus. Ongeveer $50 \%$ van de patiënten ontwikkelt na radicale cystectomie een lokaal recidief en/of metastasen [1, 2]. Voorkeurslokalisaties voor metastasen zijn regionale lymfeklieren, de lever, de longen of bot. Cutane metastasen zijn zeldzaam. De incidentie van huidmetastasen van urotheelcelcarcinoom (UCC) is ongeveer 0,84-3,6\% [3]. Doorgaans presenteren patiënten zich met urticaria, een geïsoleerde nodulaire intracutane of subcutane 
huidafwijking of 'niet-specifieke' maculaire uitslag [3-5].

\section{Casus}

Een 77-jarige vrouw werd verwezen in verband met flankpijn en hydronefrose links. Na radiologische en pathologische diagnostiek bleek er sprake van een cT3N0M0 graad 3-UCC van de blaas. Vanwege nierinsufficiëntie (geschatte GFR $42 \mathrm{ml} / \mathrm{min}$ ) was neoadjuvante cisplatin-bevattende chemotherapie gecontraindiceerd. Derhalve werd een robotgeassisteerde radicale cystectomie met lymfeklierdissectie verricht en een Brickerse deviatie aangelegd. De linkernier bleek afunctioneel en werd daarom niet aangesloten en in situ gelaten. Definitieve pathologie toonde een pT3G3N1-UCC met 1 van de 13 lymfeklieren positief (links obturatoir) en een positief snijvlak ter plaatste van de linker zijwand van de blaas en para-urethraal links. In verband met het positieve snijvlak met peroperatieve markering van het bekkenwandgebied links werd patiënte aanvullend bestraald met 66/2 Gy om de kans op lokale controle te vergroten.

Twee jaar later ontwikkelde patiënte lymfeoedeem in het linkerbeen en later ook erythemateuze afwijkingen in de linkerlies. Op de CT-abdomen en de $\mathrm{X}$-thorax van twee maanden daarvoor waren geen me-

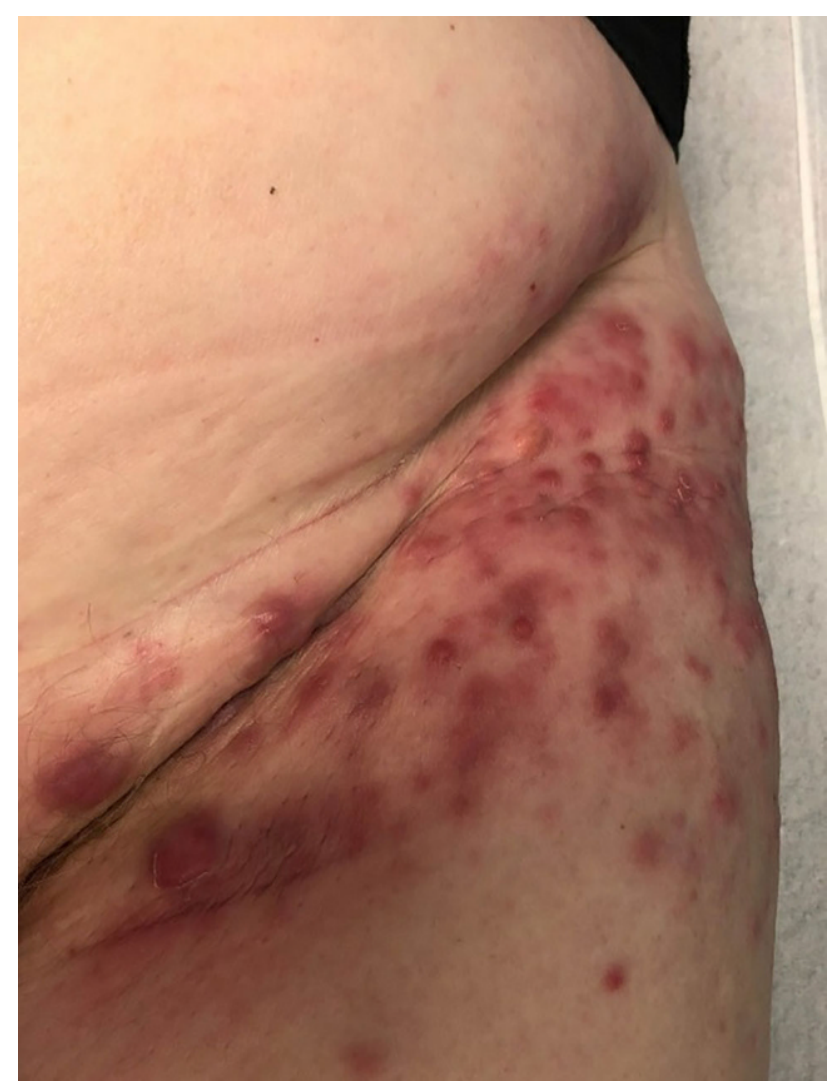

Figuur 1 Foto van de huidafwijking een aantal weken na initiële presentatie bij de dermatoloog. Differentiaaldiagnostisch werd gedacht aan herpes zoster, cutane metastasen of lymfogene metastasen met veneuze stuwing tastasen gezien. Bij verdenking op eczeem in haar lies was zij door de huisarts behandeld met triamcinolon, maar de afwijking had zich desondanks verder uitgebreid in de richting van haar linkerheup. Er trad geen jeuk of pijn op aan de huid.

In verband met de zich uitbreidende huidafwijking werd patiënte geanalyseerd op de polikliniek Dermatologie. De dermatoloog beschreef de afwijkingen als scherp afgrensbare noduli, die een dermatoom leken te volgen (fig. 1). Differentiaaldiagnostisch werd gedacht aan herpes zoster, cutane metastasen of lymfogene metastasen met veneuze stuwing. Er werd een huidbiopt genomen en dit bevestigde de diagnose cutane metastase van UCC. Patiënte werd verwezen naar de oncoloog en er werd onder andere een PET-CTscan verricht. Daarop was een matig verhoogde activiteit te zien in een groot deel van de verdikte huid links inguïnaal en van het linkerbovenbeen, verdacht voor diffuse cutane metastasering. Verder werden beiderzijds noduli gezien, zowel inguïnaal als lateraal van de linker psoasspier, verdacht voor lymfekliermetastasen. Omdat de programmed-cell death-1/ligand-1 (PD-L1) score negatief was (CPS-score 5\%) startte patiënte met palliatieve chemotherapie (carboplatine/ gemcitabine). Ongeveer een maand na de eerste chemokuur werd patiënte opgenomen op de afdeling Oncologie met algehele malaise en erysipelas van haar linkerbil en met een fors roder en groter geworden huidafwijking in haar lies (fig. 2). Vijf chemokuren later was er sprake van stabiele ziekte en liet de huidafwijking een rustiger beeld zien, waarop de chemotherapie werd gestaakt en een afwachtend beleid werd ingezet.

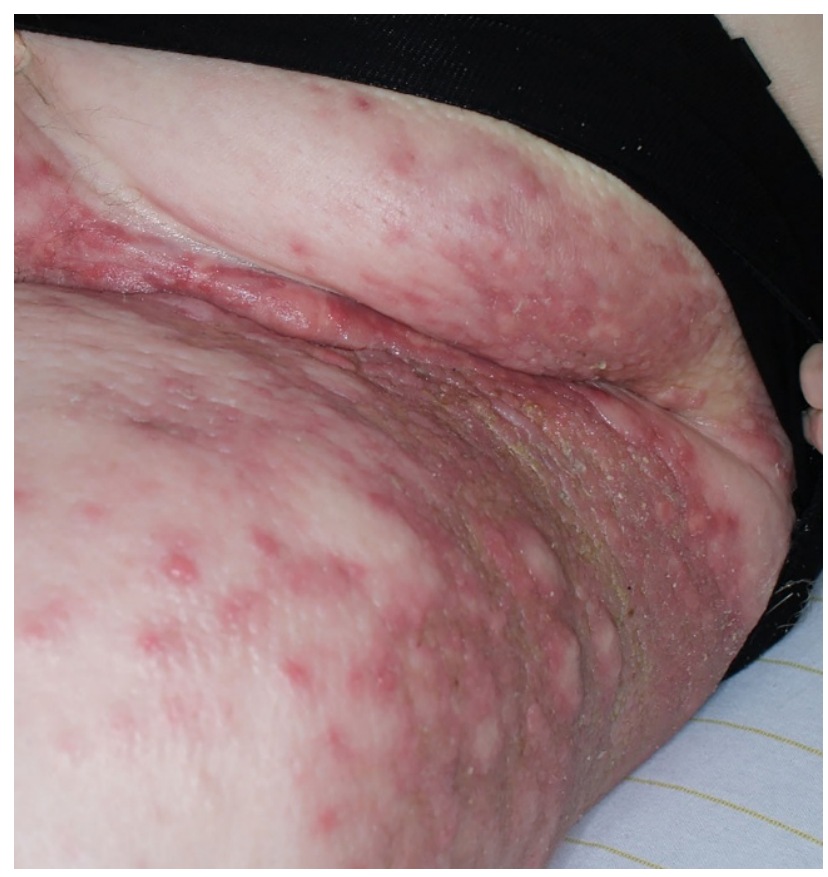

Figuur 2 Foto van de huidafwijking ongeveer een maand na de eerste chemokuur, met fors toegenomen roodheid en omvang 


\section{Discussie}

Cutane metastasen worden veroorzaakt door lymfogene en/of hematogene verspreiding van de ziekte en soms ten gevolge van tumorspill tijdens operaties [6]. Door de lymfogene verspreiding ontwikkelen cutane metastasen zich in regio's vlakbij de primaire tumor, wat in de meeste gevallen het abdomen betreft, maar ook de lies of de genitaliën [6]. In deze casus hebben zich mogelijk ook veranderingen voorgedaan in het bestraalde bekkengebied, zoals epitheliale groeifactorstimulatie of hypoxie, door verminderde immunologische afweer ter plaatse. Deze kunnen mogelijk hebben geleid tot cutane metastasering van cellen die tijdens de ingreep zijn versleept.

Vroege symptomen van progressieve ziekte kunnen wisselend zijn en soms zelfs moeilijk te onderscheiden van niet-specifieke klachten. Zo werd in deze casus de patiënte in eerste instantie bij primaire verdenking op eczeem behandeld met triamcinolonzalf. Later werd nog gedacht aan herpes zoster, omdat de huidafwijking een dermatoom leek te volgen. Indien patiënten reeds behandeld worden met systemische therapie, wordt de differentiaaldiagnose nog breder. Bij een nieuwe huidafwijking bij patiënten die systemische therapie ondergaan, kan de dermatologische differentiaaldiagnose uiteenlopen van een bijwerking van de therapie tot een opportunistische infectie [4].

Gemetastaseerd UCC heeft over het algemeen een slechte prognose [1]. In het geval van cutane metastasen van urologische tumoren, wordt in een review van Mueller et al. zelfs beschreven dat $98 \%$ van deze patiëntengroep korter leeft dan 12 maanden na de diagnose $[4,7]$. Hoewel patiënten de huidafwijking vaak zelf onder de aandacht van hun arts brengen, is er vaak vertraging in het stellen van de juiste diagnose. De uiteindelijke diagnose wordt doorgaans gesteld op basis van een huidbiopt.

Omdat cutane metastasen een ongunstige prognose hebben, bestaat de behandeling uit palliatie middels bestraling, chemotherapie of een combinatie daarvan [4, 5, 7]. In uitzonderlijke gevallen kan de huidafwijking gereseceerd worden. Patiënten met gemetastaseerd UCC van de blaas worden vaak behandeld met de combinatie gemcitabine en carboplatine of de combinatie methotrexaat, vinblastine, doxorubicine en cisplatine (MVAC) [1, 8]. Van alle tumoren is UCC een van de meest immunogene tumoren wegens de hoge mutatiefrequentie [9], waardoor in toenemende mate immunotherapie met checkpointremmers wordt ingezet. Welke plaats checkpointremmers in de behandeling van gemetastaseerd UCC moeten innemen, staat echter nog ter discussie, omdat niet duidelijk is wat de optimale behandelduur is, welke specifieke patiëntfactoren een rol spelen, en of checkpointremmers voor, na of tegelijk met chemotherapie moeten worden gegeven [9]. Op dit moment worden checkpointremmers ingezet als tweedelijnstherapie na chemotherapie, of ze worden ingezet bij patiënten met bewezen PD-L1-expressie (CPS-score $>10 \%$ ), of ze worden ingezet in studieverband. In deze casus was geen sprake van PD-L1-expressie, wat de reden was om met gemcitabine en carboplatine te starten.

\section{Conclusie}

Cutane metastasen van een UCC zijn zeldzaam en worden vaak relatief laat als dusdanig herkend. Bij een patiënt met een bekend UCC en nieuw ontstane huidafwijkingen zijn cutane metastasen een differentiaaldiagnostische overweging.

Foto's opgenomen met toestemming van de patiënt.

Open Access This article is distributed under the terms of the Creative Commons Attribution 4.0 International License (http://creativecommons.org/licenses/by/4.0/), which permits unrestricted use, distribution, and reproduction in any medium, provided you give appropriate credit to the original author(s) and the source, provide a link to the Creative Commons license, and indicate if changes were made.

\section{Literatuur}

1. Witjes AJ, Lebret T, Comperat EM, et al. Updated 2016 EAU Guidelines on muscle-invasive and metastatic bladder cancer. Eur Urol. 2017;71(3):462-75.

2. Salama A, Abdelmaksoud AM, Shawki A, Abdelbary A, Aboulkassem H. Outcome of muscle-invasive urothelial bladder cancer after radical cystectomy. Clin Genitourin Cancer. 2016;14(1):e43-e7.

3. Raghavan D. Cutaneous manifestations of genitourinary malignancy. Semin Oncol. 2016;43(3):347-52.

4. Mueller TJ, Wu H, Greenberg RE, et al. Cutaneous metastases from genitourinary malignancies. Urology. 2004;63(6):1021-6.

5. Lees AN. Cutaneous metastasis of transitional cell carcinoma of the urinary bladder eight years after the primary: a case report. J Med Case Rep. 2015;9:102.

6. BlalockTW, Haun PL, LesherJLJr.. Cutaneous metastases of transitional cell carcinoma clinically mimicking lymphatic malformation. JAm Acad Dermatol. 2011;65(4):e112-e4.

7. Block CA, Dahmoush L, Konety BR. Cutaneous metastases from transitional cell carcinoma of the bladder. Urology. 2006;67(4):846.e15-846.e17.

8. Salemis NS, Gakis C, Zografidis A, Gourgiotis S. Cutaneous metastasis of transitional cell bladder carcinoma: a rare presentation and literature review. J Cancer Res Ther. 2011;7(2):217-9.

9. NecchiA, RinkM, Giannatempo P, Raggi D, Xylinas E. Immunotherapy for metastatic urothelial carcinoma: status quo and the future. Curr Opin Urol. 2018;28(1):1-7.

drs. Isabel B. de Angst, anios urologie

dr. Joost A.P. Leijte, uroloog

drs. Olaf J.L. Loosveld, internist

drs. Hans M Westgeest, internist

drs. Ilze E.W. van Onna, uroloog 